\title{
In reply: Another pressurization system for invasive monitoring
}

\author{
Zack Dulberg, BSc • David Levin, MD • \\ Aaron Hong, MD
}

Received: 7 February 2015/ Accepted: 12 February 2015/Published online: 25 February 2015

(C) Canadian Anesthesiologists' Society 2015

\section{To the Editor,}

We appreciate the interest expressed by Ren et al. ${ }^{1}$ in our improvised system for pressurization of a transducer used for invasive monitoring. The concept we described would work with any size syringe that could attach via luer lock to the transducer. Therefore, even with a short tourniquet, there is the alternative of using a smaller syringe. Then again, the length of the tourniquet is largely determined by the fullness of the syringe (i.e., how far the plunger extends from the base); therefore, the syringe can be filled with less fluid, if needed. Finally, several tourniquets can be connected to extend the length. We originally described a standard tourniquet with a $20 \mathrm{~mL}$ syringe in our model.

With regard to safety, we did describe a mechanism to refill the syringe in a sterile manner; as well, the pressure would likely be maintained by keeping the syringe full within a few millilitres of empty. That said, the factors that would likely change pressure would be intrinsic to the physical properties of the tourniquet, including elasticity, plasticity, creep, and relaxation. A full discussion of material selection is beyond the scope of this letter; however, to monitor pressure, we advocate checking the pressure in the syringe by repositioning the stopcock at regular intervals as well as refilling the syringe to maintain pressure.
With regard to the setup suggested by Ren et al., some syringe pumps are equipped with high pressure or low flow alarms, and these might have to be turned off or reset if they are to be used as a pressure source. Conversely, if the alarms can be adjusted to indicate if flow or pressure falls outside a clinically safe range, this might add value for detecting problems with the arterial line. A distinct advantage of our solution is that it operates without a power source.

We are glad that our letter has sparked a discussion on the topic, and it is gratifying to see another innovative solution to overcome the problem of a non-functional or unavailable pressure bag.

Conflicts of interest None declared.

Funding This work did not require funding.

\section{References}

1. Ren $Q$, Wang $Y$, Chen $N$. Another pressurization system for invasive monitoring. Can J Anesth 2015; 62: this issue; DOI: 10. 1007/s12630-015-0342-y.

2. Dulberg Z, Levin D, Hong A. An improvised pressurization system for arterial lines. Can J Anesth 2015; DOI:10.1007/s12630-0140269-8.
Z. Dulberg, BSc $(\bowtie) \cdot$ D. Levin, MD · A. Hong, MD

Department of Anesthesia, St. Michael's Hospital, Toronto, ON, Canada

e-mail: zack.dulberg@mail.utoronto.ca 